\title{
A Theoretical Approach to Welfare-Optimal Calculation of Direct Costs in European Rail Regulation
}

\author{
Marco Henseler \\ Federal University of Applied Administrative Sciences, \\ Central Branch, \\ Willy-Brandt-Str. 150321 Brühl, Germany \\ E-mail: marco.henseler@hsbund.de
}

Received: Feb. 6, 2021 Accepted: Mar. 3, 2021 Online published: Mar. 11, 2021

doi:10.5296/jpag.v11i1.18282ＵRL: https://doi.org/10.5296/jpag.v11i1.18282

\begin{abstract}
The regulation of track access charges within the European Union is based on the economic principles of first and second best pricing. In order to obtain an allocative efficiency it is crucial to determine the marginal costs of operating the train services - the so-called direct costs. Even though the Implementing Regulation (EU) 2015/909 specifies the modalities for the calculation of direct costs, a broad range of different values for direct costs can be observed across Member States. However, the discussion of the level of direct costs is driven in particular by econometric, engineering and cost accounting aspects - an economic analysis is missing despite the welfare-economic concept of track access charges. For that reason, this paper discusses the welfare economic effects of different suitable values for direct costs.

It will be shown that both a welfare maximising first best track access charging and, in most cases, also a second best charging will result in boundary solutions for direct costs. However, it also becomes obvious that from a welfare-economic perspective there is no general recommendation for adopting the lowest suitable direct costs. Any allocatively efficient regulation of track access charges must consequently consider the specific situation of each market segment separately.
\end{abstract}

Keywords: rail regulation, direct costs, marginal cost pricing, Ramsey Pricing

\section{Introduction}

With the liberalisation of the railway market in the European Union, the railway infrastructure has been transformed into a non-contestable natural monopoly that requires appropriate economic regulation. This includes in particular the regulation of charges, based 
on the principles and exceptions already described in article 7(3) and article 8(1) of Directive 2001/14/EC. With the recast of the first railway package this basic approach of charging was pursued in Directive 2012/34/EU. According to article 31(3) charges (...) shall be set at the cost that is directly incurred as a result of operating the train service. The Independent Regulators' Group - Rail (2012) considers these so-called direct costs to be equal to the economic concept of (short-run) marginal costs. Hence, the charging principles imitate a marginal cost pricing (Independent Regulators' Group - Rail, 2016c) - Link (2018) refers to "a close link to marginal cost pricing" (p. 26) - which represents a first best scenario in terms of welfare economics (Independent Regulators' Group - Rail, 2016a).

As an exception to this principle, Article 32(1) allows Member States to levy mark-ups in order to obtain full recovery of the costs. Consequently, these mark-ups focus on fixed costs, which are excluded by definition from direct costs (Independent Regulators' Group - Rail, 2016b). The Independent Regulators' Group - Rail (2016a) also points out, that infrastructure managers may levy mark-ups to cover their fixed costs, provided they do not receive state compensation for this. However, under article 32(1) the level of mark-ups must additionally guarantee optimal competitiveness of rail market segments whose identification must take into account at least the pairs listed in point 1 of annex VI of Directive 2012/34/EU - such as passenger and freight services or domestic versus international services. The competitiveness of a market segment is in turn reflected by its price elasticity of demand. Hence, the exceptions in Article 32(1) of the Directive 2012/34/EU effectively describe the concept of charging according to Ramsey-Bouiteaux principles (Independent Regulators' Group - Rail, 2016a), representing a second best regulation from a welfare economics' perspective (Link, 2018).

Member States are free to decide for a first or second best regulatory approach when transposing the objectives of the Directive 2012/34/EU into national law. It is evident that in both cases the level - and thus the determination - of direct costs is crucial. For that purpose the European Commission adopted the Implementing Regulation (EU) 2015/909 on the modalities for the calculation of the cost that is directly incurred as a result of operating the train service, which is legally binding and directly applicable. In derogation from the accounting driven procedure described in Articles 3 to 5 of the regulation, that determines the direct (unit) costs from the difference between the costs of the minimum access package and the non-eligible costs (such as fixed costs), econometric and engineering cost models may be applied as well. Even though "the adoption of this regulation reduces the freedom in defining direct, marginal costs" (Bugarinović \& Bošković, 2016, p. 4), these alternative approaches to calculation and also the use of different units as proposed in Article 5 - such as vehicle kilometres, train kilometres or gross tonne kilometres - still leave "Member States a large margin of their own interpretation" (Engelhardt, 2018, p. 88) for the specification of direct costs.

This diversity is reflected in the latest updated review of charging practices by the Independent Regulators' Group - Rail (2020). Even if in 25 out of 27 States surveyed, charges were already implemented on the basis of direct costs regarding Article 31(3) of Directive 2012/34/EU - and preparations have been made in Portugal to implement a new charging 
model in the near future - the use of mark-ups was only given in 15 countries. The most frequently chosen unit was train kilometres (nine countries), in six other countries a combination of train kilometres and gross tonne kilometres and in the remaining cases gross tonne kilometres (e.g. in Finland) or a combination with other units such as seats train kilometres or path kilometres. The review also shows that various approaches are used to determine direct costs in accordance with the possibilities provided by the implementing regulation. On the one hand, econometric (e.g. in Sweden and Slovenia), engineering methods (in Belgium) or accounting models (so-called subtraction methodology) such as in Denmark, Greece and Poland are applied. On the other hand, there are also combined approaches in the Member States such as top-down econometric and bottom-up engineering methods (e.g. in France and Germany), bottom-up engineering and top-down accounting models (e.g. in Austria and Spain) or combination of all methods (The Netherlands).

Not surprisingly, there is also a wide range of different values of direct costs across the EU. In a report of the Centre on Regulation in Europe (CERRE) Link (2018) refers to values between EUR 0.67 per train kilometre for regional passenger trains and EUR 1.32 per train kilometre for freight trains in Germany (in 2018). These direct costs are based on expert judgements regarding time tabling costs, operating and maintence costs and track depreciation. In France, marginal costs take values in the range of EUR 2.785 per 1.000 gross tonne kilometres for freight trains and EUR 5.996 per 1.000 gross tonne kilometres for high speed trains (Crozet, 2018). In particular, the direct costs result from a weight-independent component (in train kilometres) and a weight-dependent component (in gross tonne kilometres) based on a translog cost function for the estimation of marginal maintenance and marginal renewal costs. In Sweden track charges are based on econometric estimates of wear and tear costs for track maintenance (Nilsson, 2018), that consider former analyses, such as Odolinski and Nilsson (2017). Taking into account the exchange rate in 2017, this results in significantly lower values between EUR 0.56 per 1.000 gross tonne-kilometres for freight trains with a lower axle load and EUR 1.54 per 1.000 gross tonne-kilometres for passenger trains with an axle load exceeding 20 tonnes. Also Sternad et al. (2017) confirm such lower values for Slovenia. In a multistage approach using a combination of multi-criteria decision analysis and expert system and an econometric approach they determine a weighted level of EUR 0.90 per 1.000 gross tonne-kilometres as marginal costs for regional railway lines.

Marschnig et al. (2019) compared the (normalised) track access charges for Germany, France, Italy, Austria, Sweden and Switzerland. The level of direct costs differed in some cases considerably (up to five times), with econometric approaches tending to lead to higher direct costs. Furthermore, Marschnig (2018) could already observe a trade-off between direct costs and mark-ups - lower direct costs generally led to higher mark-ups and vice versa. This is an important aspect, as it appears that the objective of the Implementing Regulation (EU) 2015/909 generally seeks to reduce direct costs: according to Article 3(3) current asset values can be used if they are lower than historic values, Article 5(3) clarifies that a modulation of direct costs shall not result in an increase of the direct costs on a network-wide basis and Article 7 even allows a simplified control if the level of direct costs does not exceed percentage or absolute thresholds. 


\section{Macrothink}

However, any discussions regarding the allocation of cost elements to direct costs are primarily driven by engineering and cost accounting considerations so far. It is remarkable that no studies also cover a welfare economic perspective, as the track access charge system is based on welfare economic principles regarding a first and second best pricing scheme. This paper tries to fill this gap by analysing the welfare economic implications of varying levels of direct costs. In the following, Section 2 describes the basic model and develops the framework for determining welfare effects. Section 3 and Section 4 focus on the welfare economic implications of direct costs in a first best and second best pricing scheme. Section 5 finally concludes.

\section{The Model}

Based on observed historical data in $\mathrm{t}=0$ for total costs $C_{0}$ and traffic outputs $x_{i, 0}$ in each market segment $\mathrm{i}=1, \ldots, \mathrm{n}$ we define the cost function in such a way that all fixed costs are excluded from direct costs, which is also consistent with the position of the Independent Regulators' Group - Rail (2012) and the Independent Regulators' Group - Rail (2016b), i.e.

$$
c_{0}=\sum_{i=1}^{n} \hat{c}_{i} x_{i, 0}+\sum_{i=1}^{n}\left(C_{0}-\hat{c}_{i} x_{i, 0}\right)
$$

As a result of appropriate econometric or/and engineering methods according to the European Commission's Implementing Regulation (EU) 2015/909 all values of $\hat{c}_{i} \in\left[\underline{c}_{i}, \bar{c}_{i}\right]$, with $\underline{c}_{i}$ and $\bar{c}_{\tilde{i}}$ as lower and upper boundaries, show to be suitable estimators in $\mathrm{t}=1$ for direct costs, that can also be understood as (short-run) marginal costs. Given the nature of a natural monopoly, it is reasonable to assume constant marginal costs, that is also in line with Lindberg (2009). Hence, the level of fixed costs - represented by the second term $\sum_{i=1}^{n}\left(c_{0}-\hat{c}_{i} x_{i, 0}\right)$ in eq. 1 - depends on the particular estimator for $\hat{c}_{i}$. This corresponds to the already described observations by Marschnig (2018) that higher levels of fixed costs correlate with a lower level of direct $\operatorname{costs} \hat{c}_{i}$ and vice versa.

The (estimated) demand for rail infrastructure in each market segment $i$ is given by the inverse demand functions $p_{i}=p_{i}\left(x_{i}\right)$ with $\partial p_{i} / \partial x_{i}<0$. Due to the independence of market segments in the railway infrastructure sector $\partial p_{i} / \partial x_{j}=0$ holds $\forall j=1, \ldots, \mathrm{n}$ with $\mathrm{i} \neq j$.

In $t=1$ the regulatory body finally applies a first or second best approach considering the estimators for demand and direct costs $\hat{c}_{i}$ from $t=0$. Since any traffic volumes $x_{\tilde{i}, 1}$ in $t=1$ only affect variable cost by definition, the fixed cost term in eq. 1 will remain 
unchanged, i. e. $c_{1}=\sum_{i=1}^{n} \hat{c}_{i} x_{i, 1}+\sum_{i=1}^{n}\left(c_{0}-\hat{c}_{i} x_{i, 0}\right)$. Thus, for any vectors $x_{1}=\left(x_{1,1}, \ldots, x_{n, 1}\right)$ and $\hat{C}=\left(\hat{c}_{1}, \ldots, \hat{c}_{n}\right)$ the welfare level can be described by

$$
W\left(X_{1}, \hat{C}\right)=\sum_{i=1}^{n} \int_{0}^{\mathrm{x}_{\mathrm{i}, 1}} p_{i}\left(\tilde{\mathrm{x}}_{\mathrm{i}}\right) d \tilde{\mathrm{x}}_{\mathrm{i}}-\sum_{i=1}^{n} \hat{c}_{i} x_{i, 1}-\sum_{i=1}^{n}\left(C_{0}-\hat{c}_{i} x_{i, 0}\right)
$$

In the following, we will use eq. 2 to examine the effects of lower or upper estimated values of $\hat{c}_{i}$ on welfare. Since the results may vary between a first and a second best regulatory pricing scheme, both approaches must be considered separately. In both cases, however, the general approaches must first be adapted to the specific situation described by eq. 2 .

\section{First Best Pricing}

In a first best regulatory environment the infrastructure manager sets prices at the estimated level of direct costs in each market segment in $t=1$, i. e. $p_{i, 1}^{1 s t}=\hat{c}_{i} \forall i$. Such a marginal cost pricing scheme corresponds to Article 31(3) of Directive 2012/34/EU.

As the demand for infrastructure services is determined by $p_{i}^{-1}=x_{i}\left(p_{i}\right)$ in each market segment $i$, we receive optimal traffic outputs in $t=1$ of $x_{i, 1}^{1 s t}=\left.x_{i}\left(p_{i, 1}^{1 s t}\right)\right|_{p_{i, 1}^{1 s t}=\hat{c}_{i}} \forall i$. If we substitute these solutions into eq. 2 we obtain the value function $w^{1 s t}$, that indicates the maximum welfare level, i. e. $w^{1 s t}=w\left(X_{1}^{1 s t}(\hat{c}), \hat{c}\right)$.

Given eq. 2, the effect on welfare of different values of estimated direct costs within $\left[\bar{c}_{\tilde{j}}, \bar{c}_{i}\right]$ can now be determined by applying the unconstrained envelope theorem:

$$
\frac{\partial w^{1 s t}}{\partial \hat{c}_{i}}=\left.\frac{\partial W}{\partial \hat{c}_{i}}\right|_{X_{1}=x_{1}^{1 s t}}=-\left.x_{i}\left(p_{i, 1}^{1 s t}\right)\right|_{p_{i, 1}^{1 s t}=\hat{c}_{i}}+x_{i, 0} \forall i .
$$

Since $\frac{\partial p_{\bar{i}}}{\partial x_{i}}<0$ also implies a negative slope of the inverse function $\frac{\partial x_{\bar{i}}}{\partial p_{\bar{i}}}<0$, we know from $\frac{\partial^{\mathrm{s}} W^{1 s t}}{\partial \hat{c}_{i}^{\mathrm{n}}}=-\frac{\partial x_{i}}{\partial p_{i}} \frac{\partial p_{i}}{\partial \hat{c}_{i}}=-\frac{\partial x_{i}}{\partial p_{i}}>0$, that the first order condition $\frac{\partial w^{1 s t}}{\partial \hat{c}_{i}} \equiv 0$ leads to a welfare minimum at $\left.x_{i}\left(p_{i, 1}^{1 s t}\right)\right|_{p_{i, 1}^{1 s t}=\hat{e}_{i}}=x_{i, 0}$. Hence, in contrast to a real reduction in direct costs, our case of a simple redistribution shows, that lower direct costs have a welfare-enhancing effect on the one hand by increasing the traffic volume, but on the other hand are accompanied by an increase in fixed costs, which in turn reduces welfare. Since a marginal change in direct costs changes variable costs according to the current volume of traffic $x_{i, 1}^{1 s t}$, but fixed costs according to the historical volume of traffic $x_{i, 0}$, the total impact on welfare depends on a 
comparison of the two.

It is therefore obvious that only boundary solutions can be identified as welfare-optimal direct costs, that result from a comparison of traffic volumes.

Proposition 1: A welfare-optimal first best regulation considers the following cases:

A If $\bar{c}_{\tilde{i}}$ implies a traffic volume $\left.x_{i}\left(p_{i, 1}^{1 s t}\right)\right|_{p_{i, 1}^{1 s t}=\bar{c}_{i}}>x_{i, 0}$, then charging at minimum direct costs is welfare-optimal, i.e. $p_{i_{i} 1}^{1 s t_{i}^{*}}=\hat{c}_{i}^{1 s t_{p}^{*}}=\underline{c}_{i}$.

$B$ If $\underline{c}_{i}$ implies a traffic volume $\left.x_{i}\left(p_{i, 1}^{1 s t}\right)\right|_{p_{i=1}^{1 s t}=\underline{\underline{G}}_{i}}<x_{i, 0}$, then charging at maximum direct costs is welfare-optimal, i.e. $p_{i_{i} 1}^{1 s t_{i}^{*}}=\hat{c}_{i}^{1 s t_{i *}^{*}}=\bar{c}_{i}$.

C If $\underline{c}_{i \underline{i}}$ and $\bar{c}_{\tilde{i}}$ imply traffic volumes of $\left.x_{i}\left(p_{i, 1}^{1 s t}\right)\right|_{p_{i=1}^{1 s t}=\underline{\underline{\sigma}}_{i}}>x_{i, 0}$ and $\left.x_{i}\left(p_{i, 1}^{1 s t}\right)\right|_{p_{i, 1}^{1 s t}=\bar{c}_{i}}<x_{i, 0}$, the decision for charging at $\underline{c}_{i}$ or $\bar{c}_{\tilde{i}}$ depends on the induced welfare levels, i.e.

$$
p_{i_{i}, 1}^{1 s t^{*}}=\hat{c}_{i}^{1 s t, *}=\underset{\hat{c}_{i} \in\left[\underline{c_{i}}, \overline{\left.c_{i}\right]}\right]}{\arg \max } \mathfrak{W}^{1 s t} .
$$

This shows that already in a first best regulation no general tendency towards lower direct costs can be determined.

\section{Second Best Pricing}

In a second best approach, the general objective of maximising overall economic welfare - as defined in eq. 2 - remains unchanged. However, additionally the cost recovery referred to in Article 32(1) of Directive 2012/34/EU must be taken into account, which is described by the following constraint

$$
g=: \sum_{i=1}^{n} p_{i, 1} x_{i, 1}-\sum_{i=1}^{n} \hat{c}_{i} x_{i, 1}-\sum_{i=1}^{n}\left(c_{0}-\hat{c}_{i} x_{i, 0}\right)
$$

Irrespective of the adjusted fixed cost term in eq. 4, the result of the constrained optimisation problem is determined by the well-known Ramsey-Boiteux pricing formula, i.e.

$$
\frac{p_{i, 1}^{2 n d}-\hat{c}_{i}}{p_{i, 1}^{2 n d}}=-\frac{\lambda}{1+\lambda} \cdot \frac{1}{\varepsilon_{x_{i} p_{i}}\left(p_{i, 1}^{2 n d}\right)}
$$


where $\varepsilon_{x_{i} p_{i}}\left(p_{i, 1}^{2 n d}\right)=\frac{\partial x_{i}}{\partial p_{i}}\left(p_{i, 1}^{2 n d}\right) \frac{p_{i, 1}^{\text {and }}}{x_{i}\left(p_{i, 1}^{\text {and }}\right)}$ indicates the (negative) price elasticity of demand at the optimum and $x_{i}\left(p_{i}\right)=p_{i}^{-1}$ being the demand in each market segment $i$. It is worth mentioning that this type of formulation with regard to the Lagrange multiplier $\lambda$ only follows from a Lagrange optimisation in which the $\lambda$ term - taking into account eq. 2 and eq. 4 - was added in the Lagrangian function $\mathcal{L}=W\left(X_{1}, \hat{C}\right)+\lambda g$.

Given the implicit solutions $p_{i, 1}^{2 n d}(\hat{C}) \forall i$ for expression 5 and thus also for $X_{1}^{2 n d}(\hat{C})=x_{1,1}^{2 n d}(\hat{C}), \ldots, x_{n, 1}^{2 n d}(\hat{C})$, we can set up the second best value function from eq. 2 as $W^{2 n d}=W\left(X_{1}^{2 n d}(\hat{C}), \hat{C}\right)$, which describes welfare in maximum. To determine the effect of a marginal change of any $\hat{c}_{i}$ on welfare in maximum, we use the constrained envelope theorem, that leads together with the optimal value of the Lagrange multiplier $\lambda^{2 n d}$ to

$$
\frac{\partial \mathcal{W}^{2 n d}}{\partial \hat{c}_{i}}=\left.\frac{\partial W}{\partial \hat{c}_{i}}\right|_{X_{1}=X_{1}^{2 n d}}+\left.\lambda^{2 n d} \frac{\partial g}{\partial \hat{c}_{i}}\right|_{X_{1}=X_{1}^{2 n d}}=\left(-x_{i, 1}^{2 n d}(\hat{C})+x_{i, 0}\right)\left(1+\lambda^{2 n d}(\hat{C})\right) \forall i
$$

Since eq. 5 implies $\frac{\lambda}{1+\lambda}>0$, the Lagrange multiplier can only have values of $\lambda^{2 n d}>0$ or $\lambda^{2 n d}<-1$. However, for any given values of $\hat{C}^{\prime}=\hat{c}_{1}^{\prime}, \ldots, \hat{c}_{n}^{\prime}$ and fixed costs $C_{f}^{\prime}=\sum_{i=1}^{n}\left(C_{0}-\hat{c}_{i}^{\prime} x_{i, 0}\right)$, both the Lagrange multiplier $\lambda^{2 n d}\left(\hat{C}^{\prime}\right)$ and optimal traffic volumes

$X_{1}^{2 n d}\left(\hat{C}^{\prime}\right)=x_{1,1}^{2 n d}\left(\hat{C}^{\prime}\right), \ldots, x_{n, 1}^{2 n d}\left(\hat{C}^{\prime}\right)$ are uniquely determined in their appropriate codomains.

This in turn implies that all pairs of numbers $\left(C_{0}, x_{i, 0}\right)$ leading to the given $C_{f}^{x}$ also have the same (Ramsey-Boiteux) solution $\quad X_{1}^{2 n d}\left(\hat{C}^{\prime}\right), \lambda^{2 n d}\left(\hat{C}^{\prime}\right)$ and therefore $\forall x_{i, 1}^{2 n d}(\hat{C}) \exists x_{i, 0}\left(x_{i, 0}>_{\left.x_{i, 1}^{2 n d}(\hat{C})\right)}\right.$ and $\forall x_{i, 1}^{2 n d}(\hat{C}) \exists x_{i, 0}\left(x_{i, 0} \leq x_{i, 1}^{2 n d}(\hat{C})\right)$ are true. This shows that, regardless of the specific effect of a change in $\hat{C}$ on $x_{i, 1}^{2 n d}$ and $\lambda^{2 n d}$, expression 6 can 
lead to positive or negative values.

In the case of an identity of $x_{i, 1}^{2 n d}$ and the previously observed traffic volume $x_{i, 0}$ in the considered market segment $i$ the value function is at a local extremum. In contrast to the first best scenario, however, $\frac{\partial^{\mathbb{2}} W}{\partial \hat{c}_{i}^{\mathbb{T}}}$ does not necessarily imply a welfare minimum at $x_{i, 1}^{2 n d}=x_{i, 0}$, i.e.

$$
\begin{gathered}
\left.\frac{\partial^{2} W^{2 n d}}{\partial \hat{c}_{i}^{2}}\right|_{x_{i, 1}^{\text {nnd }}=x_{i, 0}}=-\frac{\partial x_{i, 1}^{2 n d}}{\partial \hat{c}_{i}}(1+\lambda(\hat{C}))+\left.\frac{\partial \lambda^{2 n d}}{\partial \hat{c}_{i}}\left(-x_{i, 1}^{2 n d}(\hat{C})+x_{i, 0}\right)\right|_{x_{i, 1}^{\text {nnd }}=x_{i, 0}} \\
=-\frac{\partial x_{i, 1}^{\text {nnd }}}{\partial \hat{c}_{i}}(1+\lambda(\hat{C})) .
\end{gathered}
$$

Nevertheless, a maximum can always be excluded if $(\alpha) \frac{\partial x_{i 1}^{\text {nnd }}}{\partial \hat{\varepsilon}_{i}} \leq 0 \wedge \lambda(\hat{C})>0$ or ( $\beta) \frac{\partial x_{i 1}^{\text {nnd }}}{\partial \hat{c}_{i}} \geq 0 \wedge \lambda(\hat{C})<-1$ hold. In both cases we obtain again boundary solutions, determined by the comparison of $x_{i, 1}^{2 n d}(\hat{C})$ and $x_{i, 0}$ in expression 6.

Lemma 1: A non-negative effect of an increase from $\hat{c}_{\bar{i}}$ on $w^{2 \text { nd }}$ is obtained for:

$$
\begin{aligned}
& \text { (a1) } \frac{\partial x_{i, 1}^{\text {nnd }}}{\partial \hat{c}_{i}} \leq 0 \wedge \lambda(\hat{C})>0 \wedge x_{i, 0} \geq x_{i, 1}^{2 n d}(\hat{C}) \text { or } \\
& \text { ( } \beta 2) \frac{\partial x_{i, 1}^{\text {nnd }}}{\partial \hat{c}_{\hat{i}}} \geq 0 \wedge \lambda(\hat{C})<-1 \wedge x_{i, 0} \leq x_{i, 1}^{2 n d}(\hat{C}) \text {. }
\end{aligned}
$$

In the opposite case, $\frac{\partial w^{\text {and }}}{\partial \hat{\epsilon}_{i}}<0$ always results for

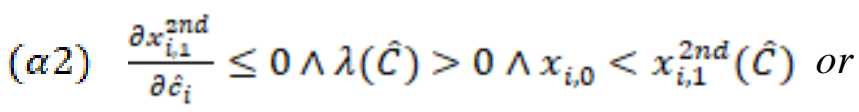

$$
\begin{aligned}
& \text { (B1) } \frac{\partial x_{i, 1}^{\text {nnd }}}{\partial \hat{c}_{i}} \geq 0 \wedge \lambda(\hat{C})<-1 \wedge x_{i, 0}>x_{i, 1}^{2 n d}(\hat{C}) \text {. }
\end{aligned}
$$

In all other cases, which are given by 
(y1) $\frac{\partial x_{i, 1}^{\text {and }}}{\partial \hat{c}_{i}}>0 \wedge \lambda(\hat{C})>0$ or

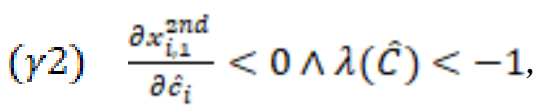

a welfare maximum finally results for $x_{i, 1}^{2 n d}=x_{i, 0}$.

It is useful to express these different constellations as sets of $\hat{c}_{\bar{i}}$, i.e. $\bar{C}_{i}=\left\{\hat{c}_{i} \mid(\alpha 1)\right.$ or $(\beta 2)$ fulfilled $\}, \underline{C}_{i}=\left\{\hat{c}_{i} \mid(\alpha 2)\right.$ or $(\beta 1)$ fulfilled $\}$ and $\tilde{C}_{i}=\left\{\hat{c}_{i} \mid(\gamma 1)\right.$ or $(\gamma 2)$ fulfilled $\}$. Then we can easily determine the optimal solutions for direct costs.

Proposition 2: Together with $\quad \tilde{c}_{i}:=\left\{\hat{c}_{i} \in\left[c_{i}, \bar{c}_{i}\right] \mid x_{i, 1}^{2 n d}\left(\hat{c}_{1}, \ldots, \hat{c}_{i, \ldots}, \hat{c}_{n}\right)=x_{i, 0}\right\} \quad a$ welfare-optimal second best charging considers the following direct costs:

$$
\begin{aligned}
& \text { A } \hat{c}_{i}^{2 n d d_{i k}^{*}}=\bar{c}_{i} \text {, if }\left[c_{i}, \bar{c}_{i}\right] \subseteq \bar{C}_{i} \text {, } \\
& B \hat{c}_{i}^{2 n d d^{*}}=\underline{c_{i}} \text {, if }\left[\underline{c}_{i}, \bar{c}_{i}\right] \subseteq \underline{C_{i}} \text {, } \\
& \text { C } \hat{c}_{i}^{2 n d_{i}^{*}}=\tilde{c}_{i} \text { if }\left[\bar{c}_{i}, \bar{c}_{i}\right] \subseteq \tilde{C}_{i} \text {, }
\end{aligned}
$$

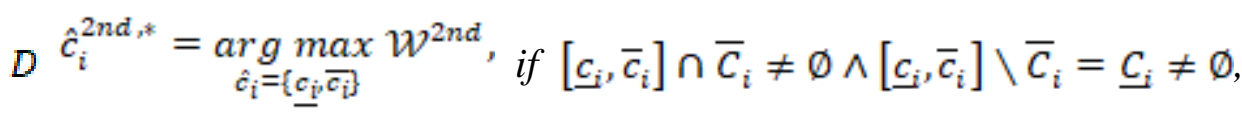

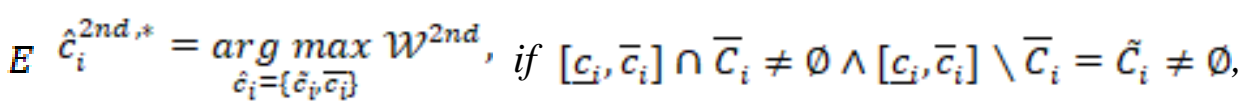

$$
\begin{aligned}
& F^{\hat{c}_{i}^{2 n d, *}}=\underset{\hat{c}_{i}=\left[\underline{c_{i}} \bar{c}_{i}\right]}{\arg \max } \mathfrak{W}^{2 n d}{ }^{2 n} \text { if }\left[c_{i}, \bar{c}_{i}\right] \cap \underline{C_{i}} \neq \emptyset \wedge\left[c_{i}, \bar{c}_{i}\right] \backslash \underline{C}_{i}=\tilde{C}_{i} \neq \emptyset \text {, }
\end{aligned}
$$

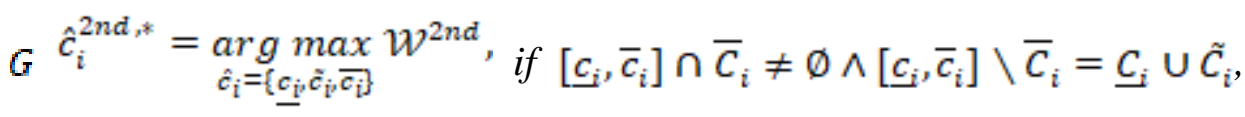

with $\underline{C_{i}} \neq \emptyset \wedge \tilde{C}_{i} \neq \emptyset$.

As already in the first best scenario, a unique solution for the level of direct costs cannot be provided either. 


\section{Conclusion}

It could be shown that there are no clear implications for both a first and a second best price setting. Lower direct costs within a market segment generally have a positive direct effect in terms of an increase in traffic volume. However, it cannot be precluded that the resulting increase in fixed costs (as an indirect effect) may overcompensate the direct effect. Thus, higher direct costs may also turn out to be economically more efficient. In the case of a first best price setting, in which losses corresponding to the level of fixed costs have to be borne by the member states, a comparison of the welfare-enhancing effect of an increased volume of traffic with the welfare-reducing increase in fixed costs is necessary. With an increase of direct costs the positive indirect effect of reducing fixed costs is initially lower than the negative direct effect, which determines a local welfare minimum and thus boundary solutions in the optimum.

In a second best price setting, the reduction of direct costs necessarily leads to a rebound effect via the distribution of fixed costs according to the market segment-specific distribution of fixed costs. Hence, both the direct and indirect effect determine the level of track access charges. However, it is not clear which effect has a stronger impact. In the case of relatively low fixed costs and thus a lower mark-up $(\lambda>0)$, the result is similar to a first best pricing, although the overall effect is even greater. Thus, boundary solutions are also welfare-optimal in this case. In the opposite scenario of higher fixed costs and mark-ups $(\lambda<-1)$, the positive indirect effect and the negative direct effect of an increase in direct costs are inverted, which determines a welfare maximum within the interval of suitable values.

These implications are far-reaching. Recommendations for both a first best and a second best approach may vary across market segments, which may lead to a consideration of high direct costs in one market segment and low direct costs in another one. Moreover, opposite solutions for first and second best charging may also occur for identical market segments. This shows that any simple recommendation like a general preference for lower direct costs cannot be confirmed - even if it should be politically desired. In no case allocative efficiency can replace any kind of cost inefficiency, even if the lowest suitable direct costs are taken into account - this can only be achieved by an effective seperate regulation of the level of costs.

However, these results should not be misunderstood - especially against the background that from an engineering perspective a greater degree of harmonisation would be expected (Marschnig et al., 2019). In particular, the finding of welfare-optimal boundary solutions in many cases does not aim to demand a wider range of direct costs. Rather any limitation of suitable values for direct costs will be reasonable as long as they are based on proven engineering and cost accounting aspects, as first and second best pricing rely on true marginal costs themselves. Although it became evident that a total harmonisation in the meaning of uniform values is neither politically necessary nor economically efficient as long as there is still room for different interpretations of the cost that is directly incurred as a result of operating the train service.

Any future modifications of both the Directive 2012/34/EU concerning the system of track access charges in the European Member States and the Implementing Regulation (EU) 
2015/909 regarding the modalities for the calculation of direct cost should not only consider engineering and cost accounting perspectives, but also focus on welfare economic aspects.

\section{References}

Bugarinović, M., \& Bošković, B. (2016). Where does costs coverage and track access charges structure go after Adoption of Regulation 2015/909/EU? International scientific-expert conference on railways (RAILCON'16), Niš.

Crozet, Y. (2018). Track access charges: reconciling conflicting objectives: Case Study France: logic and limits of full cost coverage. Centre on Regulation in Europe (CERRE), Brussels.

Engelhardt, J. (2018). Theoretical basis for calculation of charges for access to railway infrastructure in the light of European Union law. European Journal of Service Management, 25(4), 81-89. https://doi.org/10.18276/ejsm.2018.25-10

Independent Regulators' Group - Rail (2012). Position Paper on the concept of cost that is $\begin{array}{lllll}\text { directly incurred. IRG-Rail Position } & \text { Paper, }\end{array}$ https://irg-rail.eu/irg/documents/position-papers/26,2012.html

Independent Regulators' Group - Rail (2016a). Initial approach to market segment definition and criteria for an Assessment of Mark-ups in consideration of Directive 2012/34/EU. IRG-Rail Position Paper, 16(7). https://irg-rail.eu/irg/documents/position-papers/22,2016.html

Independent Regulators' Group - Rail (2016b). An introduction to the calculation of direct costs in respect of implementing regulation 2015/909. IRG-Rail Position Paper, 16(8). https://irg-rail.eu/irg/documents/position-papers/22,2016.html

Independent Regulators' Group - Rail (2016c). Updated review of charging practices for the minimum access package in Europe. IRG-Rail Position Paper, 16(10). https://irg-rail.eu/irg/documents/position-papers/22,2016.html

Independent Regulators' Group - Rail (2020). Review of charging practices for the minimum access package in Europe. IRG-Rail Position Paper, 20(10). https://irg-rail.eu/irg/documents/position-papers/263,2020.html

Lindberg, G. (2009). CATRIN (Cost Allocation of TRansport INfrastructure cost). Deliverable D 12, Conclusions and recommendations, VTI, Stockholm.

Link, H. (2018). Track access charges: reconciling conflicting objectives: Case Study Germany. Centre on Regulation in Europe (CERRE), Brussels.

Marschnig, S. (2018). Direct Costs - a first Benchmark. Track Access Charges Summit (2018, April 4), Amsterdam.

Marschnig S., Vidović, I., \& Brantegger, M. (2019). Trassenpreise auf Basis der Richtlinie 2012/34/EU - ein erster Benchmark. Der Eisenbahningenieur, 6, 6-8. 
Nilsson, J.-E. (2018). Track access charges: reconciling conflicting objectives: Case Study Sweden: Track access charges and the implementation of the SERA directive - promoting efficient use of railway infrastructure or not? Centre on Regulation in Europe (CERRE), Brussels.

Odolinski, K., \& Nilsson, J.-E. (2017). Estimating the marginal maintenance cost of rail infrastructure usage in Sweden; does more data make a difference? Economics of Transportation, 10, 8-17. https://doi.org/10.1016/j.ecotra.2017.05.001

Sternad, M., Jagrič, T., \& Rosi, B. (2017). Estimating marginal infrastructure cost in new infrastructure charging model. Technical Gazette, 24(3), 829-836. https://doi.org/10.17559/TV-20160218095139

\section{Copyright Disclaimer}

Copyright for this article is retained by the author(s), with first publication rights granted to the journal.

This is an open-access article distributed under the terms and conditions of the Creative Commons Attribution license (http://creativecommons.org/licenses/by/4.0/). 